\title{
The Influence of Computer Self-efficacy and Subjective Norms on the Students' Use of Learning Management Systems at King Abdulaziz University
}

\author{
Sami S. Binyamin, Malcolm J. Rutter, and Sally Smith
}

\begin{abstract}
Technology acceptance model (TAM) has been a standout amongst the most well-known models in understanding the users' acceptance of technologies. This study develops a model to predict the factors that influence the use of learning management systems (LMS) among higher educational students in Saudi Arabia by applying the TAM model and two psychological determinants: computer self-efficacy and subjective norms. The Partial Least Squares Structural Equation Modeling (PLS-SEM) technique was employed to examine the proposed model. The findings confirm the TAM model within the context of Saudi Arabia. Further, the students' perceived ease of use is positively influenced by computer self-efficacy, while the students' perceived usefulness is positively affected by subjective norm. As scholars have overlooked using TAM to assess LMS in the context of Saudi Arabia, the study may give a guide to future work to adopt additional factors that impact the students' utilization of LMS.
\end{abstract}

Index Terms-Computer self-efficacy, e-learning system, learning management system, subjective norms, technology acceptance model.

\section{INTRODUCTION}

Advances in information and communication technologies (ICT) have provided higher educational institutions with the opportunity to adopt many technologies in order to enhance the efficiency of learning [1]. The field of education in academic and learning settings in Saudi Arabia has been influenced by this advancement [2]. E-learning is one of the results of this development and cannot be delivered without the use of technologies. Learning management systems (LMS) have been the most popular technology for facilitating e-learning [3] and are considered the most commonly used technology in the field of education [4]. This is thanks to the accessibility and flexibility of ICT [5].

LMS have been extensively adopted in educational institutions internationally [6]. In the context of Saudi Arabia the majority of Saudi higher educational institutions (87\%) have adopted LMS where Blackboard is the dominant system [7]. However, the utilization of LMS in Saudi Arabia is minimal [5], [8]. This study aims to explore the acceptance

Manuscript received November 25, 2017; revised May 19, 2018. This research was financially supported by the Saudi Arabian Ministry of Education.

S. S. Binyamin is with King Abdulaziz University, Jeddah, Saudi Arabia $\mathrm{He}$ is also with Edinburgh Napier University, Edinburgh, United Kingdom (e-mail: ssbinyamin@kau.edu.sa).

M. J. Rutter and S. Smith are with School of Computing, Edinburgh Napier University, Edinburgh, United Kingdom (e-mail: m.rutter@napier.ac.uk, s.smith@napier.ac.uk). and actual use of LMS within the context of Saudi Arabia. As many studies have concluded that Saudi students use e-learning systems ineffectively [9], it is necessary to identify the factors that have an influence on the usage of LMS from the students' perception. The original TAM model is not useful in explaining social influence [10]; therefore, it was extended in this study, and two external variables were adopted and examined: subjective norms and computer self-efficacy. Further, the majority of LMS studies in Saudi Arabia investigated functions of LMS, technical usability and users' attitude toward the system [8]. Little research has been conducted to understand the relationship between Saudi students' LMS utilization and external factors. Moreover, most studies focus on the teachers' perspective rather than the students' [1]. Alharbi and Drew in [8] asserted that scholars have overlooked using TAM to assess LMS in the context of Saudi Arabia. Therefore, it is not surprising that TAM has rarely been employed to assess Saudi students' acceptance of LMS.

The structure of this paper is organized as follows: First, the technology acceptance model is briefly described, and the conceptual model is presented. After explaining the research methodology, the data analysis is described. The study findings are presented, followed by the discussion and conclusion section.

\section{TeChnOlogy ACCEPTANCE Model}

Many models have been utilized to investigate the acceptance and use of technologies. Technology acceptance model (TAM) has been a standout amongst the most well-known models in understanding the users' acceptance of technologies and used extensively in many studies [1], [8], [11]-[14]. According to Google Scholar, the model [15] has been cited more than 36,000 times. In 1989, TAM was developed by Fred Davis to introduce a theoretical framework based on the theory of reasoned actions (TRA) [15]. TAM explains the relationship between users and technologies to estimate the user's acceptance of the technology [16]. Most acceptance models have failed to combine the psychological and technical constructs into one theory; however, TAM is one of the theories that combines variables from both aspects [16].

The original TAM is composed of 5 constructs (see Figure 1). According to the TAM model, the acceptance of new technologies can be measured by assessing 4 determinants: perceived ease of use (PEOU), perceived usefulness (PU), attitude towards use (ATU) and behavioral intention to use 
(BIU). PEOU can be defined as the extent to which someone believes that utilizing LMS would be with minimal cognitive effort, and PU can be defined as the extent to which someone believes that utilizing LMS would improve his or her performance [15]. Fig. 1 shows that actual system use (AU) is directly influenced by BIU, which in turn is affected by both ATU and PU. ATU is directly influenced by PU and PEOU. PEOU defines PU directly, and both PEOU and PU are influenced by external factors.

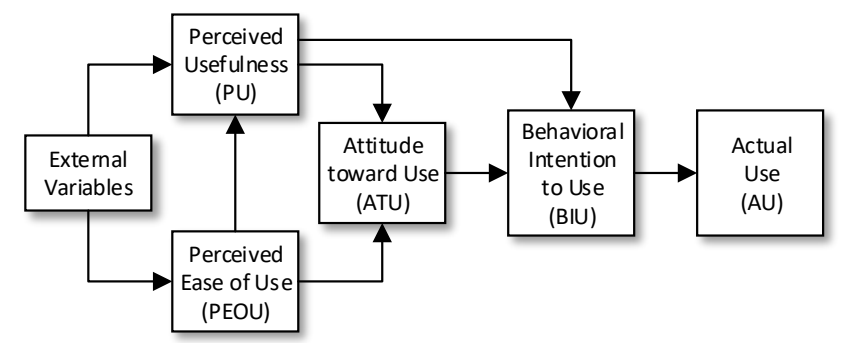

Fig. 1. Technology acceptance model (TAM) [17].

\section{CONCEPTUAL FRAMEWORK}

Based on the original TAM model and previous literature, 2 factors (computer self-efficacy and subjective norms) were employed to investigate the students' acceptance and use of LMS. Fig. 2 depicts the proposed research model. In this section, a brief description of the variables is provided, research hypotheses are listed, and the proposed research model is introduced.

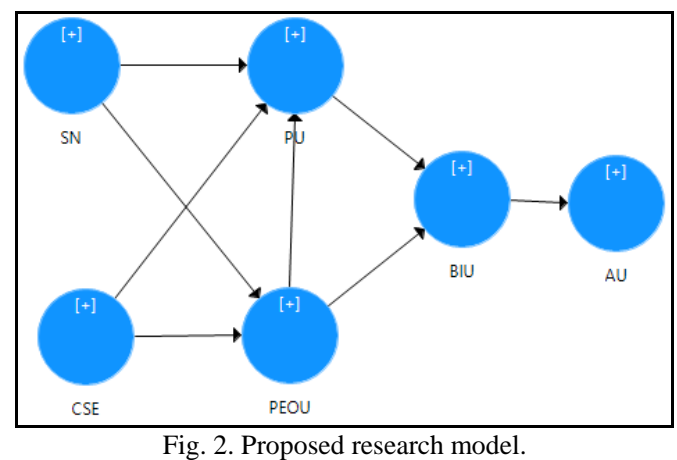

Based on the original TAM model, 4 hypotheses were proposed to assess the students' acceptance and usage of LMS at King Abdulaziz University (KAU).

- $\mathrm{H}_{1}$ : PEOU positively influences PU.

- $\mathrm{H}_{2}$ : PEOU positively influences BIU.

- $\mathrm{H}_{3}$ : PU positively influences BIU.

- $\mathrm{H}_{4}$ : BIU positively influences AU.

\section{A. Computer Self-efficacy}

The first most widely employed variable to extend TAM in the field of e-learning is computer self-efficacy (CSE) [18]. This factor was introduced as a determinant of PEOU by Venkatesh and Davis in 1996 [16]. CSE measures a person's estimation of his or her ability to use computer technologies [19]. Therefore, if an individual feels that he or she has a high ability to use computer technologies, he or she is more likely to use the system. For the purpose of this study, CSE is meant to be the students' belief regarding their ability to use the LMS provided by their institution.
CSE has been adopted extensively into TAM-related studies in the field of e-learning, and the findings are inconsistent [20]. Abdullah and Ward in [18] conducted a quantitative meta-analysis of 107 studies in e-learning adoption and concluded that 17 out of 27 (63\%) studies found a positive influence between CSE and PU and 33 out of 41 $(80 \%)$ studies found a positive influence between CSE and PEOU. In the studies [21]-[23] of developing countries (as the case of Saudi Arabia), it was found that CSE influences PEOU of e-learning and does not affect PU. It was found that CSE of Jordanian students is correlated with PEOU [24]. In [25], it was concluded that CSE does not influence PU of e-learning systems. In Saudi Arabia, CSE has been said to affect the students' PEOU and PU of e-learning systems based on TAM [26]. The TAM3 model [27] and Venkatesh's model [28] tested the effect of CSE and postulated that CSE influences PEOU. Based on TAM3, [29] demonstrated this postulation in Saudi Arabia.

The relationships between CSE and TAM's constructs are depicted in Fig. 2. The authors assume that students with high CSE are more likely to use LMS. To test the influence of CSE on the students' use of LMS, the following hypotheses were proposed.

- $\mathrm{H}_{5}$ : CSE positively influences PEOU.

- $\mathrm{H}_{6}$ : CSE positively influences PU.

\section{B. Subjective Norm}

The second most widely employed variable to extend TAM in the field of e-learning is subjective norm (SN) [18]. Scholars use the terms social influence and subjective norm interchangeably [20]. This factor indicates the degree to which individuals feel that others think they should or should not perform a particular behavior [30]. In this study, if a student feels that people important to him or her believe that he or she should use an LMS, he or she is more likely to use the system. It is reasonable that subjective norm affects the usage of technologies in developing countries [31]. Various models tested the effect of SN, such as TRA [32], TPB [33], TAM2 [30], TAM3 [27] and UTAUT [34]. Comparing to the other models, one of the limitations in TAM is the lack of success to take a proper care of social influence factors that affect individuals' behavioral intention and actual use of the system under investigation [35]. Therefore, SN was adopted as an external factor into TAM.

The influence of $\mathrm{SN}$ on the constructs of TAM in e-learning has been studied in the literature, and the findings are contradictory [20]. It was concluded that 19 out of 22 $(86 \%)$ researches indicated a positive influence between SN and PU and 4 out of $6(67 \%)$ researches indicated a positive influence between SN and PEOU [18]. The influence of SN on PU of e-learning was demonstrated in [21], which contradicts with the results of [22]. In [36], it was concluded that $\mathrm{SN}$ affects PU of e-learning systems and does not affect PEOU. In Jordan, it was found that SN is correlated with PU [24]. TAM2 model [30] and TAM3 model [27] tested the effect of SN and postulated that SN influences PU. Based on TAM3, [29] demonstrated this postulation in Saudi Arabia.

The relationships between SN and TAM's constructs are depicted in Fig. 2. The authors assume that students with high $\mathrm{SN}$ are more likely to use LMS. To test the influence of SN 
on the students' use of LMS, the following hypotheses were proposed.

- $\mathrm{H}_{7}$ : $\mathrm{SN}$ positively influences PEOU.

- $\mathrm{H}_{8}$ : SN positively influences PU.

\section{Methodology}

This section describes the method used for data collection. The development of the instrument used, participants' profiles and the study sample are discussed in this section. The data analysis is described at the end of the section.

\section{A. Data Collection}

As TAM is quantitative in nature, the decision was made to use online survey for data collection [21]. Althobaiti and Mayhew asserted that surveys are suitable for the evaluation of LMS [37]. As Google Docs service is free of charge, mobile-friendly and easy to use and provides a variety of questions, it was used for collecting data from the participants. The users of learning management systems, studying at KAU in different colleges and levels of education were the target of this study. Due to the appropriateness in terms of resources and wide usage in technology acceptance research [20], the non-probability convenience sampling technique was used. The online survey was available for 3 weeks, and the link to the survey was sent by email to the participants. However, the majority of students did not show willingness to fill in the survey and only 31 responses were received. Consequently, the decision was made to distribute the survey manually. Eventually, 150 surveys were received, and 142 surveys were employed for the data analysis stage.

\section{B. Instrumentation}

The survey used for this study consists of 2 sections. The first one includes the students' profiles or demographic information and includes 6 items: age, gender, prior experience with LMS, education level, field of study and GPA (grade point average). The second section addresses the original TAM constructs and the external variables (see appendix). The 29 items can be answered using a 7-point Likert scale, where 1 indicates that students strongly disagree with the statements and 7 indicates that students strongly agree with the statements [8], [13], [14], [16], [21]. The constructs consist of PEOU (5 statements), PU (5 statements), BIU (5 statements), AU (4 statements), CSE (5 statements) and SN (5 statements). To ensure the reliability and validity, the 29 items were adopted mainly from previous literature [8], [15], [21], [36], [38]. Further, all the instruments were closed questions [14], [38].

At the first stage, the survey was developed in English and reviewed by 2 native English speakers to ensure that it is free of wording problems. Then, the English version of the survey was translated to Arabic by a bilingual speaker since Arabic is the native language in Saudi Arabia. As the back-translation method was used in [8], the Arabic version was reviewed by 2 bilingual speakers. Further, it is worth mentioning that the word LMS was replaced with Blackboard since Blackboard is the LMS in use there.

\section{Data Analysis}

After the completion of the data collection stage, the collected data were entered into SPSS Statistics 23.0 for descriptive statistical tests. In an earlier paper [1], the data set was used and analyzed using the regression analysis statistical technique. In this study, the Partial Least Squares Structural Equation Modeling (PLS-SEM) technique was employed to examine the proposed research model [39] using SmartPLS software version 3.2.7 [40]. Even though regression analysis has been used for simple modeling, it is not able to examine unobserved variables, indirect effects and complex models [41]. Therefore, PLS-SEM is more suitable for complex and causal modeling [42]. PLS-SEM requires the examination of the indicators' reliability, the constructs' reliability, the convergent validity, the discriminant validity and hypothesis testing [43], given in the next section.

\section{FINDINGS}

In this section, the findings of the research are tabulated. The results are composed of demographic information, descriptive statistics, the reliability and validity results and the hypothesis testing.

\section{A. Demographic Information}

The students' profiles are summarized in Table I. 123 students $(86.6 \%)$ are male, and 19 students (13.4\%) are female. The majority of the students $(66.9 \%)$ are within the range of 21 and 25 years old. All students have at least 1 year of experience with LMS. Regarding the education level, the majority of the participants are students with a bachelor's degree $(73.2 \%)$. The study includes students from different disciplines and fields.

TABLE I: PARTICIPANTS' DEMOGRAPHIC INFORMATION

\begin{tabular}{|c|c|c|c|}
\hline Characteristics & Groups & $\mathbf{N}$ & $\%$ \\
\hline \multirow[t]{2}{*}{ Gender } & Male students & 123 & 86.6 \\
\hline & Female students & 19 & 13.4 \\
\hline \multirow[t]{4}{*}{ Age } & $<21$ & 28 & 19.7 \\
\hline & $21-25$ & 95 & 66.9 \\
\hline & $26-30$ & 11 & 7.7 \\
\hline & $>30$ & 8 & 5.6 \\
\hline \multirow{3}{*}{$\begin{array}{l}\text { Experience with } \\
\text { LMS }\end{array}$} & $<1$ year & 70 & 49.3 \\
\hline & $1-2$ years & 48 & 33.8 \\
\hline & $>2$ years & 24 & 16.9 \\
\hline \multirow[t]{4}{*}{ Education Level } & Diploma & 19 & 13.4 \\
\hline & Bachelor & 104 & 73.2 \\
\hline & Master & 16 & 11.3 \\
\hline & $\mathrm{PhD}$ & 3 & 2.1 \\
\hline \multirow[t]{4}{*}{ Field of Study } & Medical Science & 21 & 14.8 \\
\hline & Applied Science & 48 & 33.8 \\
\hline & Natural Science & 22 & 15.5 \\
\hline & Humanities and Social Sciences & 51 & 35.9 \\
\hline \multirow[t]{3}{*}{ GPA } & $0-2.99$ & 16 & 11.3 \\
\hline & $3-3.99$ & 66 & 46.5 \\
\hline & $4-5$ & 60 & 42.3 \\
\hline
\end{tabular}

\section{B. Descriptive Statistics}

Table II summarizes the means and standard deviation values of the students' responses for the 29 items. All the mean values are above 4.73 , which demonstrate that the LMS is perceived positively among students. Among the two external variables, students rated computer self-efficacy as the most influential factor on LMS usage followed by 
subjective norm. However, perceived ease of use was the highest among the original constructs of TAM. The standard deviation values are within the range of 1.14 and 1.52 , which indicate that the data is very close to the mean.

\section{The Reliability Test}

The reliability was examined in terms of indicators' reliability and constructs' reliability as recommended by [43]. The indicators' reliability is acceptable when the loadings are greater than 0.7 , while the constructs' reliability is acceptable when the values of Cronbach's alpha and composite reliability (CR) are greater than 0.7 [43], [44], [45]. Loadings with high values indicate that the indicators of a latent variable are quite similar [43]. It is worth mentioning that even though the loadings of PU01, AU02 and CSE04 are slightly below the threshold, the indicators were eliminated. Table II demonstrates the high reliability of the indicators and constructs.

TABLE II: RELIABILITY TEST RESULTS

\begin{tabular}{|c|c|c|c|c|c|c|}
\hline 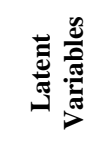 & 莺 & : & 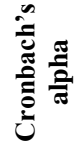 & ชี & $\sum_{\Sigma}^{\Xi}$ & 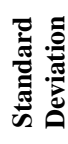 \\
\hline \multirow[t]{5}{*}{ PEOU } & PEOU01 & 0.888 & \multirow[t]{5}{*}{0.896} & \multirow[t]{5}{*}{0.924} & \multirow[t]{5}{*}{5.45} & \multirow[t]{5}{*}{1.14} \\
\hline & PEOU02 & 0.874 & & & & \\
\hline & PEOU03 & 0.886 & & & & \\
\hline & PEOU04 & 0.700 & & & & \\
\hline & PEOU05 & 0.850 & & & & \\
\hline \multirow[t]{5}{*}{$\mathbf{P U}$} & PU01 & 0.692 & \multirow[t]{5}{*}{0.876} & \multirow[t]{5}{*}{0.910} & \multirow[t]{5}{*}{5.23} & \multirow[t]{5}{*}{1.28} \\
\hline & PU02 & 0.795 & & & & \\
\hline & PU03 & 0.879 & & & & \\
\hline & PU04 & 0.864 & & & & \\
\hline & PU05 & 0.853 & & & & \\
\hline \multirow[t]{5}{*}{ BIU } & BIU01 & 0.812 & \multirow[t]{5}{*}{0.934} & \multirow[t]{5}{*}{0.950} & \multirow[t]{5}{*}{5.19} & \multirow[t]{5}{*}{1.52} \\
\hline & BIU02 & 0.888 & & & & \\
\hline & BIU03 & 0.933 & & & & \\
\hline & BIU04 & 0.885 & & & & \\
\hline & BIU05 & 0.927 & & & & \\
\hline \multirow[t]{4}{*}{$\mathbf{A U}$} & AU01 & 0.874 & \multirow[t]{4}{*}{0.842} & \multirow[t]{4}{*}{0.898} & \multirow[t]{4}{*}{4.74} & \multirow[t]{4}{*}{1.48} \\
\hline & AU02 & 0.617 & & & & \\
\hline & AU03 & 0.911 & & & & \\
\hline & AU04 & 0.892 & & & & \\
\hline \multirow[t]{5}{*}{ SN } & SN01 & 0.757 & \multirow[t]{5}{*}{0.863} & \multirow[t]{5}{*}{0.901} & \multirow[t]{5}{*}{5.28} & \multirow[t]{5}{*}{1.23} \\
\hline & SN02 & 0.867 & & & & \\
\hline & SN03 & 0.834 & & & & \\
\hline & SN04 & 0.791 & & & & \\
\hline & SN05 & 0.765 & & & & \\
\hline \multirow[t]{5}{*}{ CSE } & CSE01 & 0.855 & \multirow[t]{5}{*}{0.868} & \multirow[t]{5}{*}{0.904} & \multirow[t]{5}{*}{5.30} & \multirow[t]{5}{*}{1.36} \\
\hline & CSE02 & 0.900 & & & & \\
\hline & CSE03 & 0.902 & & & & \\
\hline & CSE04 & 0.648 & & & & \\
\hline & CSE05 & 0.716 & & & & \\
\hline
\end{tabular}

\section{The Validity Test}

The validity was tested in terms of the convergent validity and discriminant validity as recommended by [43]. Convergent validity means that the indicators of one latent variable are positively correlated with each other [46]. Convergent validity can be achieved when the average variance extracted (AVE) is 0.5 or higher [44]. AVE is calculated by adding the squared loadings of the indicators of one latent variable and dividing them by the number of indicators [43]. Discriminant validity confirms that the latent variable is unlike the other latent variables [44]. Specifically, discriminant validity means that each latent variable has more correlation with its indicators than with the other latent variables [43]. Table III demonstrates that the convergent validity and discriminant validity were achieved.

\begin{tabular}{|c|c|c|c|c|c|c|c|}
\hline$\frac{\frac{d}{d}}{\frac{d}{d}}$ & $\frac{1}{4}$ & 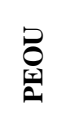 & 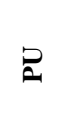 & $\underset{\emptyset}{\varrho}$ & $\underset{Z}{Q}$ & Z & 效 \\
\hline PEOU & 0.7 & 0.84 & & & & & \\
\hline PU & 0.7 & 0.62 & 0.82 & & & & \\
\hline BIU & 0.8 & 0.54 & 0.76 & 0.89 & & & \\
\hline $\mathbf{A U}$ & 0.7 & 0.42 & 0.51 & 0.60 & 0.83 & & \\
\hline SN & 0.7 & 0.37 & 0.54 & 0.68 & 0.56 & 0.80 & \\
\hline CSE & 0.7 & 0.61 & 0.55 & 0.50 & 0.51 & 0.47 & 0.81 \\
\hline
\end{tabular}

\section{E. Testing the Hypotheses}

Using SmartPLS, the proposed research model and hypotheses were examined. Table IV summarizes the results of the path analysis test and indicate that most of the proposed paths are supported. The majority of the relationships maintain a high level of significance. The strongest path coefficient is presented in the relationship between PU and BIU; however, the weakest path coefficient is presented in the relationship between SN and PEOU. In terms of the coefficient of determination (R2), the predictive power of PU is 0.511 (high), PEOU is 0.379 (moderate), BIU is 0.582 (high) and $\mathrm{AU}$ is 0.360 (moderate).

\begin{tabular}{|c|c|c|c|c|c|}
\hline & 䒿 & ت્气 & 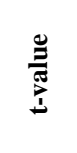 & 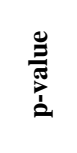 & 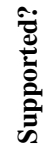 \\
\hline $\mathbf{H}_{1}$ & $\mathrm{PEOU} \rightarrow \mathrm{PU}$ & 0.417 & 5.585 & 0.000 & Yes \\
\hline $\mathbf{H}_{2}$ & $\mathrm{PEOU} \rightarrow \mathrm{BIU}$ & 0.111 & 1.246 & 0.213 & No \\
\hline $\mathbf{H}_{3}$ & $\mathrm{PU} \rightarrow \mathrm{BIU}$ & 0.689 & 8.847 & 0.000 & Yes \\
\hline $\mathbf{H}_{4}$ & $\mathrm{BIU} \rightarrow \mathrm{AU}$ & 0.600 & 8.485 & 0.000 & Yes \\
\hline $\mathbf{H}_{5}$ & $\mathrm{CSE} \rightarrow$ PEOU & 0.558 & 7.297 & 0.000 & Yes \\
\hline $\mathrm{H}_{6}$ & $\mathrm{CSE} \rightarrow \mathrm{PU}$ & 0.152 & 1.669 & 0.096 & No \\
\hline $\mathbf{H}_{7}$ & $\mathrm{SN} \rightarrow \mathrm{PEOU}$ & 0.107 & 1.330 & 0.184 & No \\
\hline $\mathbf{H}_{8}$ & $\mathrm{SN} \rightarrow \mathrm{PU}$ & 0.312 & 4.388 & 0.000 & Yes \\
\hline
\end{tabular}

\section{DISCUSSION}

As little research has been done to understand students' use of LMS, this study was conducted to investigate the factors that influence the students' utilization of LMS. Similar to other studies [1], [2], [8], [11], [26], [47] this study emphasizes the robustness of using TAM as a theoretical model in understanding the acceptance and usage of e-learning, particularly in Saudi higher educational institutions. The study at hands aimed to examine two external variables (computer self-efficacy and subjective norms) that contribute to the appropriate use of LMS in Saudi Arabia. Generally speaking, the results prove that students in Saudi Arabia perceive LMS positively. This provides an indication of the students' acceptance of e-learning and an evidence that Saudi Arabia is fertile soil for educational development and technology adoption.

The path analysis test reveals that most of the proposed 
paths and hypotheses are supported, and the relationships between the original TAM constructs [15] are demonstrated. Particularly, perceived ease of use has a positive influence on perceived usefulness $(\beta=0.417, p<0.001)$. In the earlier work done by the authors [1], this relationship is supported with higher estimation $(\beta=0.618, p<0.001)$. Other studies [11], [14], [21], [26], [29], [47], in e-learning are consistent with this result. Additionally, perceived usefulness has a positive effect on behavioral intention $(\beta=0.689, p<0.001)$. In line with [15], this relationship has the strongest path coefficient. Various studies [11], [14], [21], [26], [29], [47]-[49] in e-learning are in line with the same finding. The students' behavioral intention strongly influences actual use $(\beta=0.600, p<0.001)$ as in [11], [14], [21]. However, perceived ease of use does not have a positive influence on behavioral intention. In accordance to the original TAM [15], Davis did not postulate a direct effect between perceived ease of use and behavioral intention. The result is consistent with [14], [48] but not consistent with [21], [25], [26], [29], [47], [50]. Consequently, $\mathrm{H}_{1}, \mathrm{H}_{3}$ and $\mathrm{H}_{4}$ are completely supported, but $\mathrm{H}_{2}$ is rejected.

The students' computer self-efficacy is hypothesized to positively influence perceived ease of use $\left(\mathrm{H}_{5}\right)$. The findings indicate that perceived ease of use is directly affected by computer self-efficacy $(\beta=0.558, p<0.001)$. This meets the assumptions of TAM3 model [27] and Venkatesh's model [28]. Similar result was reached in other e-learning studies [22], [23], [26], [29], [51]. As hypothesized, students with higher computer self-efficacy are more likely to perceive LMS easy to use. In line with [18], the result indicates that computer self-efficacy is the strongest predictor of perceived ease of use. Compared to the earlier work published by the authors [1], this relationship is supported with slightly higher estimation $(\beta=0.572, p<0.001)$. Therefore, $\mathrm{H}_{5}$ is supported.

It was hypothesized that students with higher computer self-efficacy are more likely to perceive LMS useful. However, the findings proved the opposite. In comparison to the authors' work [1], this hypothesis is supported $(\beta=0.537$, $p<0.001)$. This might be attributed to the use of the rigorous PLS-SEM, more suitable for unobserved variables, indirect effects and causal models [41], [42]. Even though this is not the case in [26] and [51], the result is consistent with [22], [23], [25]. In [26], regression analysis technique was used for data analysis, whereas [51] was conducted in China. It was reported that the factors that influence the use of LMS might be different from one country to another [52]. Thus, $\mathrm{H}_{6}$ is not supported. Nevertheless, computer self-efficacy positively affects perceived usefulness indirectly through perceived ease of use.

Subjective norm was hypothesized to positively influence perceived ease of use. However, the findings indicate that perceived ease of use is not influenced by subjective norm. Similar finding was also found in [36]. Hence, $\mathrm{H}_{7}$ is not supported. Moreover, subjective norm does not affect perceived ease of use indirectly.

The students' perceived usefulness is positively affected by subjective norm $(\beta=0.312, p<0.001)$. This meets the assumptions of TAM2 model [30] and TAM3 model [27]. The result is consistent with e-learning studies [29], [36], [50], [53] but not consistent with [22]. In line with [18], this indicates that subjective norm is the strongest predictor of perceived usefulness. As hypothesized, students with higher subjective norm are more likely to perceive LMS useful. In the earlier work done by the authors [1], this relationship is supported with higher estimation $(\beta=0.512, p<0.001)$. Therefore, $\mathrm{H}_{8}$ is supported.

\section{CONCLUSION}

As TAM has been used in limited manners to explain students' utilization of LMS within the context of Saudi Arabia [8], the findings might provide the stakeholders of higher educational institutions with insights regarding the Saudi students' perspective of LMS. The results of the study may interest researchers, teachers, students, ministry of education and higher educational institutions in Saudi Arabia. Further, the research provides fundamentals for LMS acceptance and usage; so, the study provides directions to the stakeholders of higher educational institutions during the development stage of LMS to ensure the adoption of the proposed factors.

Linking the results to real life, this paper tries communicating two clear messages to higher educational institutions. First, investing more money on the students' computer skills and building their confidence about their ability to use computer technologies will impact the students' utilization of LMS. Second, the efforts of higher educational institutions should not be limited to the adoption of new technologies into education. Promoting and advising students contributes to better use of LMS. This study concludes that computer self-efficacy and subjective norm are two necessary factors that influence the students' use of LMS, which contribute to their academic achievements and performance as demonstrated by [54] that the use of Blackboard is correlated with the students' final grade.

\section{LIMITATIONS AND FUTURE WORK}

The study is not free of limitations. The sample of the experiment includes only 19 female students and $3 \mathrm{PhD}$ students. For this reason, another study might be conducted to expand the sample to include more female and $\mathrm{PhD}$ students. Additionally, the participants were students at a single institution. The scope of the study could be expanded to include students from different academic institutions or universities in Saudi Arabia. This study took two external variables into account, future research could consider the investigation of other variables in the context of Saudi Arabia. In addition, the research proposed model could be more complex by examining the moderation effect of personal characteristics, such as gender, age and experience. Finally, this study investigated the perceptions of only the students. Later, teachers and administrators can be added to the scope of the study.

\section{APPENDIX}

TABLE V: THE STATEMENTS USED IN THE INSTRUMENT

\begin{tabular}{|l|l|}
\hline Items & \multicolumn{1}{|c|}{ Statements } \\
\hline Perceived ease of use \\
\hline PEOU $_{1}$ & It is easy to learn how to use Blackboard. \\
\hline
\end{tabular}




\begin{tabular}{|c|c|}
\hline $\mathrm{PEOU}_{2}$ & It is easy to become a skillful at using Blackboard. \\
\hline $\mathrm{PEOU}_{3}$ & It is easy to operate Blackboard. \\
\hline $\mathrm{PEOU}_{4}$ & Blackboard is flexible to interact with. \\
\hline $\mathrm{PEOU}_{5}$ & Overall, Blackboard is easy to use. \\
\hline \multicolumn{2}{|c|}{ Perceived usefulness } \\
\hline $\mathrm{PU}_{1}$ & Blackboard would enable me to achieve tasks more quickly. \\
\hline $\mathrm{PU}_{2}$ & Using Blackboard would improve my learning performance. \\
\hline $\mathrm{PU}_{3}$ & Using Blackboard would help me learn effectively \\
\hline $\mathrm{PU}_{4}$ & $\begin{array}{l}\text { Using Blackboard would make it easier to achieve learning } \\
\text { tasks. }\end{array}$ \\
\hline $\mathrm{PU}_{5}$ & Overall, Blackboard is useful. \\
\hline \multicolumn{2}{|c|}{ Behavioral intention to use } \\
\hline $\mathrm{BIU}_{1}$ & I would like to use Blackboard in the future if I have the chance \\
\hline $\mathrm{BIU}_{2}$ & I would like to use Blackboard in all future courses. \\
\hline $\mathrm{BIU}_{3}$ & I would recommend using Blackboard to others. \\
\hline $\mathrm{BIU}_{4}$ & I would encourage my teachers to use Blackboard in courses. \\
\hline $\mathrm{BIU}_{5}$ & I will continue using Blackboard in the future. \\
\hline \multicolumn{2}{|c|}{ Actual use } \\
\hline $\mathrm{AU}_{1}$ & I use Blackboard frequently. \\
\hline $\mathrm{AU}_{2}$ & I tend to use Blackboard for as long as is necessary. \\
\hline $\mathrm{AU}_{3}$ & I have been using Blackboard regularly. \\
\hline $\mathrm{AU}_{4}$ & I usually get involved with Blackboard. \\
\hline \multicolumn{2}{|c|}{ Subjective norms } \\
\hline $\mathrm{SN}_{1}$ & Blackboard is important for university students. \\
\hline $\mathrm{SN}_{2}$ & Blackboard is important for university students. \\
\hline $\mathrm{SN}_{3}$ & My colleagues at KAU think I should use Blackboard. \\
\hline $\mathrm{SN}_{4}$ & People think I should use Blackboard. \\
\hline $\mathrm{SN}_{5}$ & I would like to do what my teacher thinks I should do. \\
\hline \multicolumn{2}{|c|}{ Computer self-efficacy } \\
\hline $\mathrm{CSE}_{1}$ & I usually achieve the tasks in Blackboard without help. \\
\hline $\mathrm{CSE}_{2}$ & I have the skills needed to use Blackboard. \\
\hline $\mathrm{CSE}_{3}$ & I learned how to use Blackboard easily. \\
\hline $\mathrm{CSE}_{4}$ & I know about many computer technologies. \\
\hline $\mathrm{CSE}_{5}$ & $\begin{array}{l}\text { If I face a problem in Blackboard, I usually know what I should } \\
\text { do. }\end{array}$ \\
\hline
\end{tabular}

\section{ACKNOWLEDGEMENT}

The authors would like to thank King Abdualziz University and the Saudi Arabian Ministry of Education for facilitating data collection and for the financial support of the study. Great gratitude is expressed for Mr. Ahmed Al-Shehri, $\mathrm{PhD}$ student at Edinburgh Napier University, for his assistance in the Arabic translation of the survey.

\section{REFERENCES}

[1] S. Binyamin, M. Rutter, and S. Smith, "Factors influencing the students' use of learning management systems: A case study of King Abdulaziz University," presented at International Conference on e-Learning (ICEL2017), Orlando, FL, USA, 2017.

[2] I. Y. Al-Youssef, "Student acceptance and use of internet-based distance education in Saudi Electronic University (SEU): A mixed method study," ProQuest, 2015.

[3] L. Abazi-Bexheti, A. Kadriu, and L. Ahmedi, "Measurement and assessment of learning management system usage," presented at 6th WSEAS International Conference on Educational Technologies, 2010.

[4] A. J. Swart, "The effective use of a learning management system still promotes student engagement!" presented at 2016 IEEE Global Engineering Education Conference (EDUCON), 2016.

[5] H. I. Alsaied, "Use of blackboard application in language teaching: Language teachers' perceptions at KAU," International Journal of Applied Linguistics and English Literature, vol. 5, no. 6, pp. 43-50, 2016.

[6] E. Dahlstrom, D. C. Brooks, and J. Bichsel, "The current ecosystem of learning management systems in higher education: Student, faculty, and IT perspectives," ECAR, Louisville, CO, 2014.

[7] Y. Aljuhney and L. Murray, "A comparison of the utilization of e-learning management systems in the Republic of Ireland and Kingdom of Saudi Arabia: A case study (2015)," International Journal on Recent and Innovation Trends in Computing and Communication (IJRITCC), vol. 4, no. 2, pp. 1-12, 2016.

[8] S. Alharbi and S. Drew, "Using the technology acceptance model in understanding academics' behavioural intention to use learning management systems," International Journal of Advanced Computer Science and Applications (IJACSA), vol. 5, no. 1, pp. 143-155, 2014.

[9] R. S. Al-Jarf, "Cultural issues in online collaborative instruction in EFL classrooms," presented at Third International Online Conference on Second and Foreign Language Teaching and Research, 2007.

[10] A. Tarhini, K. Hone, and L. Xiaohui, "Extending the TAM model to empirically investigate the students' behavioural intention to use e-learning in developing countries," presented at Science and Information Conference (SAI), London, 2013.

[11] S. Binyamin, M. Rutter, and S. Smith, "The students' acceptance of learning management systems in Saudi Arabia: A case study of King Abdulaziz University," presented at 11th Annual International Conference of Technology, Education and Development (INTED2017), Valencia, Spain, 2017.

[12] K. A. Al-Busaidi and H. Al-Shihi, "Instructors' acceptance of learning management systems: A theoretical framework," Communications of the IBIMA, vol. 2010, no. 2010, 2010.

[13] H.-Y. Yoon, "User acceptance of mobile library applications in academic libraries: An application of the technology acceptance model," The Journal of Academic Librarianship, 2016.

[14] H. Mohammadi, "Investigating users' perspectives on e-learning: An integration of TAM and IS success model," Computers in Human Behavior, vol. 45, no. 2015, pp. 359-374, 2015.

[15] F. D. Davis, "Perceived usefulness, perceived ease of use, and user acceptance of information," MIS Quarterly, vol. 13, no. 3, pp. 319-340, 1989.

[16] H. Holden and R. Rada, "Understanding the influence of perceived usability and technology self-efficacy on teachers' technology acceptance," Journal of Research on Technology in Education, vol. 43 , no. 4, 2011.

[17] F. D. Davis, R. P. Bagozzi, and P. R. Warshaw, "User acceptance of computer technology: A comparison of two theoretical models," Management Science, vol. 35, no. 8, pp. 982-1003, 1989.

[18] F. Abdullah and R. Ward, "Developing a general extended technology acceptance model for e-learning (GETAMEL) by analysing commonly used external factors," Computers in Human Behavior, vol. 56, no. 2016, pp. 238-256, 2016

[19] D. R. Compeau and C. A. Higgins, "Computer self-efficacy: Development of a measure and initial test," MIS Quarterly, pp. 189-211, 1995.

[20] A. Tarhini, K. Hone, and X. Liu, "The effects of individual differences on e-learning users' behaviour in developing countries: A structural equation model," Computers in Human Behavior, vol. 41, no. 2014, pp. 153-163, 2014.

[21] R. Ramirez-Anormaliza, F. Sabaté, and X. Llinàs-Audet, "The acceptance and use of the e-learning systems among the university teachers in Ecuador," presented at EDULEARN16, Barcelona, Spain, 2016.

[22] F. Kanwal and M. Rehman, "Factors affecting e-learning adoption in developing countries-empirical evidence from Pakistan's higher education sector," IEEE Access, vol. 5, no. 2017, pp. 2169-3536, 2017.

[23] R. Boateng, A. S. Mbrokoh, L. Boateng, P. K. Senyo, and E. Ansong, "Determinants of e-learning adoption among students of developing countries," The International Journal of Information and Learning Technology, vol. 33, no. 4, pp. 248-262, 2016.

[24] M. O. A. Hashim, "Factors affecting the adoption of web-based learning management system by students in higher education: The case of Jordan," ProQuest, 2011.

[25] C.-M. Ma, C.-M. Chao, and B.-W. Cheng, "Integrating technology acceptance model and task-technology fit into blended e-learning system," Journal of Applied Sciences, vol. 13, no. 5, pp. 736-742, 2013

[26] N. F. Al-Mushasha, "Determinants of e-learning acceptance in higher education environment based on extended technology acceptance model," presented at 2013 Fourth International Conference on e-Learning" Best Practices in Management, Design and Development of e-Courses: Standards of Excellence and Creativity", 2013.

[27] V. Venkatesh and H. Bala, "Technology acceptance model 3 and a research agenda on interventions," Decision Sciences, vol. 39, no. 2, pp. 273-315, 2008

[28] V. Venkatesh, "Determinants of perceived ease of use: integrating control, intrinsic motivation, and emotion into the technology acceptance model," Information Systems Research, vol. 11, no. 4, pp. 342-365, 2000.

[29] S. S. Al-Gahtani, "Empirical investigation of e-learning acceptance and assimilation: A structural equation model," Applied Computing and Informatics, vol. 11, no. 3, pp. 158-169, 2016. 
[30] V. Venkatesh and F. D. Davis, "A theoretical extension of the technology acceptance model: Four longitudinal field studies," Management Science, vol. 46, no. 2, pp. 186-204, 2000.

[31] E. W. Baker, S. S. Al-Gahtani, and G. S. Hubona, "Cultural impacts on acceptance and adoption of information technology in a developing country," Journal of Global Information Management, vol. 18, no. 3, pp. 35-58, 2010.

[32] M. Fishbein and I. Ajzen, Belief, Attitude, Intention and Behavior: An Introduction to Theory and Research, New York, NY: Addison-Wesley Pub, 1975.

[33] I. Ajzen, "The theory of planned behavior," Organizational Behavior and Human Decision Processes, vol. 50, no. 2, pp. 179-211, 1991.

[34] V. Venkatesh, M. G. Morris, G. B. Davis, and F. D. Davis, "User acceptance of information technology: Toward a unified view," MIS Quarterly, vol. 27, no. 3, pp. 425-478, 2003.

[35] R. P. Bagozzi, "The legacy of the technology acceptance model and a proposal for a paradigm shift," Journal of the Association for Information Systems, vol. 8, no. 4, 2007.

[36] S. Y. Park, "Analysis of the technology acceptance model in understanding university students' behavioral intention to use e-learning," Educational Technology \& Society, vol. 12, no. 3, pp. $150-162,2009$

[37] M. M. Althobaiti and P. Mayhew, "Assessing the usability of learning management system: User experience study," presented at International Conference on e-Learning, e-Education, and Online Training, 2016.

[38] R. H. Shroff, C. C. Deneen, and E. M. Ng, "Analysis of the technology acceptance model in examining students' behavioural intention to use an e-portfolio system," Australasian Journal of Education Rechnology, vol. 27, no. 4, pp. 600-618, 2011.

[39] V. Muniasamy, I. M. Eljailani, and M. Anandhavalli, "Prediction of learner perception and acceptance of e-learning system for learning with TAM (Technology Acceptance Model) in King Khalid University, Kingdom of Saudi Arabia," International Journal of Emerging Technology and Advanced Engineering, vol. 4, no. 9, pp. 94-99, 2014.

[40] C. M. Ringle, S. Wende, and J.-M. Becker, "SmartPLS 3," SmartPLS, Bönningstedt, 2015.

[41] P. B. Lowry and J. Gaskin, "Partial least squares (PLS) structural equation modeling (SEM) for building and testing behavioral causal theory: When to choose it and how to use it," IEEE Transactions on Professional Communication, vol. 57, no. 2, pp. 123-146, 2014.

[42] M. A. Ong and F. Puteh, "Quantitative data analysis: Choosing between SPSS, PLS and AMOS in social science research," International Interdisciplinary Journal of Scientific Research, vol. 3 , no. 1, pp. 14-25, 2017.

[43] J. F. Hair, G. T. Hult, C. M. Ringle, and M. Sarstedt, A Primer on Partial Least Squares Structural Equation Modeling (PLS-SEM), 2 ed., Los Angeles, CA: SAGE, 2017.

[44] J. F. Hair, M. Sarstedt, L. Hopkins, and V. G. Kuppelwieser, "Partial least squares structural equation modeling (PLS-SEM): An emerging tool in business research," European Business Review, vol. 26, no. 2, pp. 106-121, 2014.

[45] J. F. Hair, C. M. Ringle, and M. Sarstedt, "PLS-SEM: Indeed a silver bullet," Journal of Marketing Theory and Practice, vol. 19, no. 2, pp. 139-152, 2011.

[46] U. Sekaran and R. Bougie, Research Methods for Business: A Skill-Building Approach, 6th ed., 7, Ed., Chichester, UK: Wiley \& Sons Ltd., 2016.

[47] A. Al-Aulamie, "Enhanced technology acceptance model to explain and predict learners' behavioural intentions in learning management systems," University of Bedfordshire, Luton, UK, 2013.

[48] M. Amin, A. Akter, and A. Azhar, "Factors affecting private university students' intention to adopt e-learning system in Banglades," Daffodil International University Journal of Business and Economics, vol. 10, no. 2, pp. 10-25, 2016.
[49] A. R. Alenezi, "E-learning acceptance: Technological key factors for successful students' engagement in e-learning system," presented at 2012 International Conference on e-Learning, e-Business, Enterprise Information Systems, and e-Government, 2012.

[50] F. Rejón-Guardia, J. Sánchez-Fernández, and F. Muñoz-Leiva, "The acceptance of microblogging in the learning process: The UBAM model," Journal of Technology and Science Education, vol. 3, no. 1, pp. $31-47,2013$

[51] M. Chow, D. K. Herold, T.-M. Choo, and K. Chan, "Extending the technology acceptance model to explore the intention to use second life for enhancing healthcare education," Computers \& Education, vol. 59, no. 2012, pp. 1136-1144, 2012.

[52] M. M. Alkharang, "Factors that influence the adoption of e-learning: An empirical study in Kuwait," Brunel University London, London, UK, 2014.

[53] A. H. Moghadam and S. Bairamzadeh, "Extending the technology acceptance model for e-learning: A case study of Iran," presented at 2009 Sixth International Conference on Information Technology: New Generations, 2009.

[54] L. P. Macfadyen and S. Dawson, "Mining LMS data to develop an "early warning system" for educators: A proof of concept," Computers \& Education, vol. 54, no. 2, pp. 588-599, 2010.

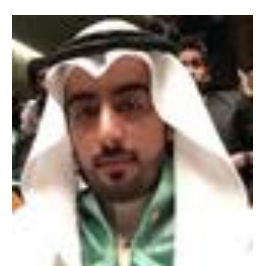

Sami S. Binyam is currently a $\mathrm{PhD}$ candidate at the School of Computing, Edinburgh Napier University, United Kingdom. He has a master's degree in information systems from Eastern Michigan University, USA and a bachelor's degree in computer science from King Abdulaziz University, Saudi Arabia. In 2012, Mr. Binyamin was a senior systems analyst at Riyad Bank, Saudi Arabia. he has been a lecturer at the department of computer and information technology, King Abdulaziz University since 2014. His research interests are usability, technology acceptance models and e-learning acceptance.

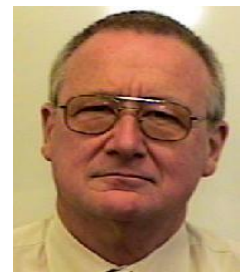

Malcolm J. Rutter trained as a communications engineer. His research experience started with his $\mathrm{PhD}$ in adaptive digital filtering. In the $\mathrm{PhD}$, Dr. Rutter was working on mathematical algorithms, of the sort that are nowadays found inside integrated circuits in applications such as mobile phones and sea divers' communication equipment. In Napier, he worked with optics projects. He mainly worked on fibre-optics for communications, and the use of passive infra-red detection for identifying people by their gait. In the School of computing, Dr. Rutter has done a lot of teaching in the field of $\mathrm{HCI}$, which interests him greatly, and web design. He has published on the topic of student communications in education, which combines his interests in $\mathrm{HCI}$, education and communication. More recently he has become involved in evaluating e-government, involving his interests in web design and HCI.

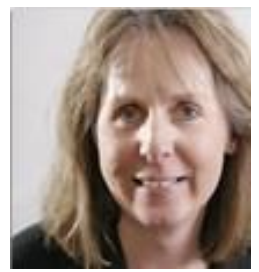

Sally Smith has an MA in mathematics from Aberdeen University, an MSc in computer science from City University, London and a DBA from Edinburgh Napier University. She is the dean of Computing at Edinburgh Napier University and project director of e-placement, Scotland. Prior to joining academia in 1992, she was a software engineer in the telecoms industry. She is also the director of the Computing Education Research Centre and her research interests are digital skills development and graduate employability. Dr. Smith is a Fellow of the British Computer Society and a Principal Fellow of the Higher Education Academy. 